\title{
The effect of intrauterine environment and low glomerular number on the histological changes in diabetic glomerulosclerosis
}

Received: 7 April 2005 / Accepted: 21 August 2005 / Published online: 9 December 2005

(C) Springer-Verlag 2005

\begin{abstract}
Aims/hypothesis: We tested the hypothesis that diabetic glomerulosclerosis would develop more rapidly in animals with fewer glomeruli. Methods: We studied the female offspring of Wistar rats that had been fed a low-protein diet (LPD) containing $6 \%$ protein or a normal-protein diet (NPD) containing $18 \%$ protein during pregnancy. Streptozotocin diabetes was induced at 12 weeks and animals were killed at 40 weeks. Results: Non-diabetic LPD offspring were of lower birthweight than the NPD offspring (5.19 \pm 0.64 vs $6.45 \pm 0.67 \mathrm{~g}, p<0.001)$ and had fewer glomeruli $(27,402 \pm 3,137$ vs $34,203 \pm 6,471, p<0.05)$. Glomerular volume correlated inversely with glomerular number $(r=-0.64$, $p=0.035$ ), but total glomerular filtration surface area was reduced in the LPD animals $\left(4,770 \pm 541\right.$ vs $5,779 \pm 1,302 \mathrm{~mm}^{2}$, $p=0.05$ ). Other renal structural and functional parameters were similar. In LPD and NPD diabetic animals, glomerular volume and basement membrane width were significantly increased compared to their respective controls. Podocyte density was lowest in the LPD diabetic animals (not significant), and the area covered by each podocyte was greater in the LPD diabetic group $\left(2.40 \pm 0.693 \times 10^{-3} \mathrm{~mm}^{2}\right)$ than in the LPD control group $\left(1.68 \pm 0.374 \times 10^{-3} \mathrm{~mm}^{2}, p<0.001\right)$ and in the NPD diabetic animals $\left(1.71 \pm 0.291 \times 10^{-3} \mathrm{~mm}^{2}, p<0.05\right)$. There was no difference in any other structural or functional parameter between the LPD and NPD diabetic animals. Conclusions/ interpretation: A decrease in glomerular number was not del-
\end{abstract}

S. E. Jones · K. E. White $\cdot$ S. M. Marshall $(\bowtie)$

Diabetes Research Group, School of Clinical Medical Sciences, University Of Newcastle upon Tyne,

Newcastle upon Tyne, UK

e-mail: s.m.marshall@ncl.ac.uk

Tel.: +44-191-222-7019

Fax: +44-191-222-0723

\section{A. Flyvbjerg}

Department of Experimental Medicine, University of Aarhus, Aarhus, Denmark eterious to renal structure and function over 40 weeks in this animal model. Further work in models with progressive renal impairment and hypertension is necessary to clarify the impact of glomerular number on the development of renal disease.

Keywords Diabetic glomerulosclerosis · Glomerular number · Intrauterine environment · Podocyte ·

Streptozotocin diabetes

Abbreviations GBM: glomerular basement membrane • GN: total glomerular number - LBW: low birthweight LPD: low-protein diet - MGV: mean glomerular volume . NBW: normal birthweight - NPD: normal-protein diet $N_{\mathrm{V}}$ : numerical density of glomeruli $\cdot P_{\text {glom }}$ : number of fine points hitting glomeruli $\cdot P_{\text {kid }}$ : number of coarse points hitting the reference area -SBP: systolic blood pressure UAER: urine albumin excretion rate $\cdot V_{\mathrm{V}}$ : glomerular volume density

\section{Introduction}

The Barker hypothesis suggests that an intrauterine insult, leading to low birthweight, predisposes to the development of chronic diseases such as hypertension, cardiovascular disease and diabetes $[1,2]$. Animals of low birthweight (LBW) induced by protein deprivation in utero have smaller kidneys with lower numbers of glomeruli than animals of normal birthweight (NBW) [3, 4]. Although some compensatory hypertrophy of the remaining nephrons occurs, it is likely that the total glomerular filtration surface area remains low. However, detailed histological analysis of the kidney in LBW animals is lacking, most studies reporting only glomerular volume and capillary length, or using semiquantitative scoring systems only.

Hypertension is more common in LBW individuals [1, 2], probably because of a reduction in the glomerular filtration surface area [5]. This combination of reduced glomerular number, reduced filtration surface area and hypertension is believed to result in an increased incidence and accelerated progression of non-diabetic renal diseases [6-8]. 
Table 1 Pre-diabetes data

\begin{tabular}{llllll}
\hline & Low-protein diet & & \multicolumn{2}{l}{ Normal-protein diet } & ANOVA $p$ \\
\cline { 2 - 3 } & Control & Diabetic & Control & Diabetic \\
\hline Birthweight $(\mathrm{g})$ & $5.19 \pm 0.64^{* * *}$ & $4.68 \pm 0.67^{* * *}$ & $6.45 \pm 0.67$ & $7.00 \pm 0.85$ \\
Body weight $(\mathrm{g})$ at 12 weeks & $233 \pm 18.1^{*}$ & $235 \pm 13.7^{*}$ & $253 \pm 37.7$ & $255 \pm 21.7$ & $<0.001$ \\
SBP (mm Hg) at 12 weeks & $122 \pm 9$ & $120 \pm 10$ & $115 \pm 11$ & $118 \pm 8$ & 0.004 \\
UAER (mg/24 h) & $0.28(0.12-1.45)$ & $0.46(0.12-1.68)$ & $0.43(0.11-1.21)$ & $0.51(0.12-6.96)$ & 0.164 \\
\hline
\end{tabular}

Sixteen animals in each group

Mean \pm SD or median (range)

ANOVA $p$ is the $p$ value by analysis of variance across all four groups

$* p<0.05$ vs respective NPD group, post hoc corrected for multiple testing

$* * * p<0.001$ vs respective NPD group, post hoc corrected for multiple testing

$S B P$ systolic blood pressure, UAER urine albumin excretion rate

Diabetic nephropathy is characterised by progressive rises in urinary albumin excretion rate and blood pressure, with declining glomerular filtration and eventually glomerulosclerosis [9]. There is accumulation of basement membrane and mesangial matrix, widening and effacement of the foot processes of podocytes, and loss of podocytes. The decline in glomerular filtration rate correlates with the reduction in glomerular filtration surface area [10].

We hypothesise that when individuals with LBW and thus reduced glomerular number and lower total filtration surface area develop diabetes, they will be at increased risk of nephropathy, which will progress more rapidly than nephropathy in NBW individuals who develop diabetes. There is some support for this, in that several studies have shown that men with type 1 diabetes and nephropathy [11] and men and women with microalbuminuria [12] are shorter than their peers without nephropathy, adult height being used as a surrogate for LBW. To test this hypothesis, we have used a rat model of LBW and reduced glomerular number, achieved by protein deprivation in utero. We have demonstrated previously in LBW animals that the acute renal adaptation is altered after 1 week of diabetes [13]. In this study we explore the long-term consequences of diabetes in this model of LBW and reduced glomerular number.

\section{Materials and methods}

Animal care

Animal experiments were carried out in accordance with the 1986 UK Home Office Regulations. For 1 week before timed mating and during pregnancy, female Wistar rats (Charles River, Margate, Kent, UK) were fed a low-protein diet (LPD) containing $6 \%$ casein or a normal-protein diet (NPD) containing 18\% casein (Usine d'Alimentation Laboratories, Lille, France). Diets were isocaloric with a similar source of protein, carbohydrate and lipid. The LPD contained supplemental methionine $(0.3 \%$ vs $0.23 \%)$.

Female offspring were weighed at birth and cross-fostered to NPD periparturient lactating dams so that the rats were only exposed to LPD in utero. Following weaning, at 21 days, rats were housed in cages at $21 \pm 2^{\circ} \mathrm{C}$ with a cycle of $12 \mathrm{~h}$ light (0600-1800 hours), and free access to water and standard rat chow.

Pre-diabetes procedures

Body weight was measured weekly from weaning until 12 weeks of age. Urine albumin excretion rate (UAER) and chow consumption were measured at weeks 4,8 and 12 .

Table 2 Metabolic parameters after 28 weeks of diabetes (study week 40)

\begin{tabular}{|c|c|c|c|c|c|}
\hline & \multicolumn{2}{|l|}{ Low-protein diet } & \multicolumn{2}{|c|}{ Normal-protein diet } & \multirow[t]{2}{*}{ ANOVA $p$} \\
\hline & Control & Diabetic & Control & Diabetic & \\
\hline Body weight $(\mathrm{g})$ week 40 & $333 \pm 19.9 *$ & $234 \pm 20.8 * \dagger$ & $353 \pm 56.7$ & $270 \pm 30.9 \dagger$ & $<0.001$ \\
\hline Chow consumption $(\mathrm{g})$ & $21.3 \pm 3.6$ & $45.5 \pm 5.1 \dagger$ & $20.5 \pm 3.1$ & $50.7 \pm 6.7 \dagger$ & $<0.001$ \\
\hline Fructosamine (mmol/l) & $296 \pm 54$ & $362 \pm 69 \dagger$ & $301 \pm 26$ & $396 \pm 67 \dagger$ & $<0.001$ \\
\hline $\mathrm{SBP}(\mathrm{mmHg})$ & $111 \pm 16$ & $110 \pm 10$ & $111 \pm 11$ & $116 \pm 9$ & 0.124 \\
\hline UAER (mg/24 h) & $2.94(0.40-68.4)$ & $27.5 \dagger(2.51-99.1)$ & $2.62(0.37-45.0)$ & $14.8 \dagger(2.35-113.5)$ & $<0.001$ \\
\hline Serum creatinine $(\mu \mathrm{mol} / 1)$ & $49 \pm 7$ & $45 \pm 10$ & $49 \pm 6$ & $54 \pm 20$ & 0.239 \\
\hline Creatinine clearance $(\mathrm{ml} / \mathrm{min})$ & $1.5 \pm 0.4$ & $2.6 \pm 0.6 \dagger$ & $1.7 \pm 0.3$ & $2.8 \pm 1.0 \dagger$ & $<0.001$ \\
\hline
\end{tabular}

Sixteen animals in each group

ANOVA $p$ is the $p$ value by analysis of variance across all four groups

$* p<0.05$ vs respective NPD group, post hoc corrected for multiple testing

$\dagger p<0.001$ vs respective control group, post hoc corrected for multiple testing

$S B P$ systolic blood pressure, $U A E R$ urine albumin excretion rate 
Systolic blood pressure (SBP) was estimated at the same time points using an indirect tail cuff method.

Diabetes study

At 12 weeks of age, LPD and NPD rats were randomly assigned to control or diabetic groups. Diabetes was induced by intravenous injection of streptozotocin, $50 \mathrm{mg} / \mathrm{kg}$ body weight. During the first week of diabetes, weight and tail vein blood glucose were measured (Accutrend meter; Roche Diagnostics, Welwyn Garden City, UK) daily between 0900 and 1000 hours. Thereafter, measurement of weight, tail vein blood glucose and urine analysis for glucose and ketones were performed weekly, with UAER, chow consumption and SBP quantified every 4 weeks. At 40 weeks of age (28 weeks after induction of diabetes), tail vein blood was taken for fructosamine and creatinine measurement for the calculation of creatinine clearance.

\section{Perfusion fixation}

At 28 weeks post-diabetes, anaesthesia was induced using a cocktail of $1 \mathrm{ml}$ Hypnorm (Janssen Pharmaceutica, Beerse, Belgium) and $1 \mathrm{ml}$ midazolam $(5 \mathrm{mg} / \mathrm{ml}$; Roche Products, Welwyn Garden City, UK) diluted in $2 \mathrm{ml}$ water for injection, at a dose of $0.27 \mathrm{ml} / 100 \mathrm{mg}$ body weight. The right kidney was removed and frozen in liquid nitrogen. Total body perfusion was performed using $4 \%$ phosphate-buffered formalin and $1 \%$ glutaraldehyde. The left kidney was removed, stripped of its capsule and weighed before storage in $4 \%$ phosphate-buffered formalin at $4^{\circ} \mathrm{C}$. Kidneys from eight randomly selected animals from each group were processed for light and electron microscopy.

\section{Light microscopy}

Each left kidney was cut into 2-mm slices using a razor blade fractionator [14]. Alternate slices were dehydrated in graded alcohol and embedded in methacrylate resin. Blocks were serially sectioned at $20-\mu \mathrm{m}$ intervals using a Universal Reichert Jung microtome. Every tenth section and its adjacent section were selected for the estimation of glomerular number by the dissector fractionator technique [15]. Sections were stained with periodic acid Schiff and viewed using an Olympus light microscope with video camera attachment.

\section{Estimation of glomerular number}

One section from each pair was designated the reference section and the other the look-up section. The reference section was moved systematically in 5-mm steps on the microscope stage and each image was captured with the camera and Image-Pro software. The corresponding areas in the look-up slide were found and the two images were viewed side by side on the computer screen at a magnification of $\times 85$.
An unbiased two-dimensional counting frame was superimposed on the images and the number of glomeruli appearing in the reference but not the look-up section was counted. To improve efficiency, the roles of the reference and look-up sections were then reversed. The total glomerular number (GN) per kidney was then calculated from:

$\mathrm{GN}=1 / f_{1} \times 1 / f_{2} \times 1 / f_{\mathrm{a}} \times \sum Q^{-} / 2$

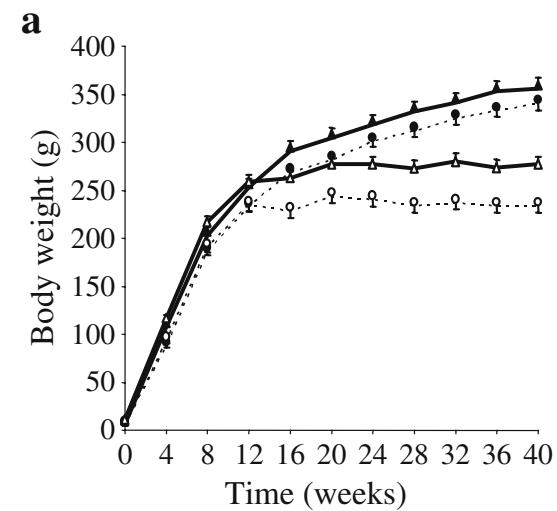

b
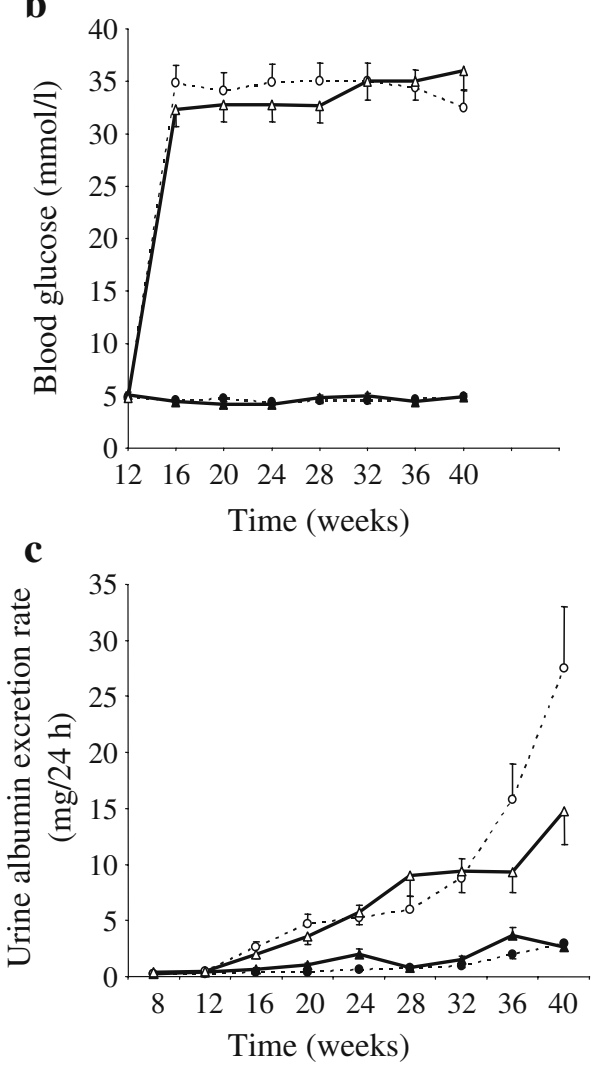

Fig. 1 Changes in body weight (a), blood glucose (b) and urinary albumin excretion rate (c) throughout the study in control and diabetic female offspring of animals fed a normal-protein diet (control, black triangle; diabetic, open triangle) or low-protein diet (control, black circle; diabetic, open circle) during pregnancy. Diabetes was induced at 12 weeks 
Where $f_{1}=$ sampling fraction $1 ; f_{2}=$ sampling fraction 2 ; $f_{\mathrm{a}}=$ sampled area; $Q^{-}=$number of glomeruli counted. The numerical density of glomeruli $\left(N_{\mathrm{V}}\right)$ was calculated from:

$N_{\mathrm{v}}=\left(\sum Q^{-} / 2\right) / a \times t \times \sum P_{\mathrm{f}}$

Where $P_{\mathrm{f}}=$ points on reference area; $a=$ area represented by $\mathrm{P}_{\mathrm{f}} ; t=$ section thickness.

Estimation of glomerular volume

One slide from each pair was selected randomly and areas were sampled as above. A grid of coarse and fine points was superimposed and the numbers of coarse points hitting the reference area $\left(P_{\mathrm{kid}}\right)$ and of fine points hitting glomeruli $\left(P_{\text {glom }}\right)$ were counted. The glomerular volume density $\left(V_{\mathrm{V}}\right)$ was calculated from:

$V_{\mathrm{V}}=\left(P_{\text {glom }} / P_{\text {kid }}\right) \times R$

where $R=$ ratio of coarse to fine points.

Mean glomerular volume (MGV) was calculated from the formula:

$\mathrm{MGV}=V_{\mathrm{V}} / N_{\mathrm{V}}$

\section{Electron microscopy}

Small pieces of cortical tissue $\left(1 \mathrm{~mm}^{3}\right)$ were postfixed in osmium tetroxide, dehydrated in graded alcohol and em- bedded in epoxy resin. Ultrathin sections were taken from three glomeruli per animal, stained with uranyl acetate and lead citrate, and examined using a Philips CM100 electron microscope. The whole glomerular profile was photographed for the estimation of mesangial volume fraction by point counting [16], podocyte number was estimated by the method of Weibel $[17,18]$ and surface densities were calculated using the line intercept method [19]. To obtain absolute surfaces, densities were multiplied by glomerular volume. The surfaces measured were the filtration surface (peripheral basement membrane), mesangio-capillary and mesangio-urinary surfaces. The sums of the filtration and mesangio-urinary surfaces were calculated to estimate the total surface area of glomerular basement membrane (GBM) underlying the podocytes. Higher magnification micrographs were systematically randomly sampled for the estimation of GBM width, and foot process width $[16,20]$.

\section{Laboratory methods}

Aliquots of 24-hour urine were stored at $-40^{\circ} \mathrm{C}$ before the urine albumin concentration was estimated by singleantibody radioimmunoassay with polyethylene glycol precipitation [21]. The intra-assay and inter-assay coefficients of variation were less than $5 \%$ and $10 \%$, respectively. Serum and urine creatinine were measured by an automated Jaffé reaction, with correction for the prevailing glucose concentration. Fructosamine was assayed using the Fructosamine Test Plus (Hoffman-La Roche, Basel, Switzerland), as described previously [22].

Table 3 Renal parameters

\begin{tabular}{|c|c|c|c|c|c|}
\hline & \multicolumn{2}{|l|}{ Low-protein diet } & \multicolumn{2}{|c|}{ Normal-protein diet } & \multirow[t]{2}{*}{ ANOVA $p$} \\
\hline & Control & Diabetic & Control & Diabetic & \\
\hline Kidney weight (g) & $0.93 \pm 0.08$ & $1.53 \pm 0.15^{* \dagger}$ & $1.02 \pm 0.17$ & $1.83 \pm 0.2 \dagger$ & $<0.001$ \\
\hline Kidney weight : body weight ratio & $0.273 \pm 0.024$ & $0.656 \pm 0.070 \dagger$ & $0.287 \pm 0.031$ & $0.672 \pm 0.062 \dagger$ & $<0.001$ \\
\hline Glomerular number & $27402 \pm 3137^{*}$ & $26971 \pm 3540^{*}$ & $34203 \pm 6471$ & $33615 \pm 2875$ & 0.009 \\
\hline Mean glomerular volume $\left(\times 10^{6} \mu \mathrm{m}^{3}\right)$ & $1.38 \pm 0.23$ & $1.84 \pm 0.24 \dagger$ & $1.20 \pm 0.35$ & $1.69 \pm 0.22$ & 0.002 \\
\hline GBM width (nm) & $263 \pm 28$ & $294 \pm 13 \ddagger$ & $272 \pm 18$ & $304 \pm 26 \ddagger$ & 0.003 \\
\hline$V_{\mathrm{v}} \mathrm{mes} / \mathrm{glom}$ & $0.168 \pm 0.029$ & $0.181 \pm 0.022$ & $0.160 \pm 0.014$ & $0.175 \pm 0.030$ & 0.393 \\
\hline Mesangio-urinary surface $\left(\mathrm{mm}^{2}\right)$ & $0.070 \pm 0.014$ & $0.102 \pm 0.023 \dagger$ & $0.075 \pm 0.019$ & $0.094 \pm 0.020$ & 0.007 \\
\hline Podocyte number & $157 \pm 42$ & $138 \pm 37$ & $163 \pm 26$ & $174 \pm 35$ & 0.283 \\
\hline Podocyte density $\left(\times 10^{-6}\right.$ per $\left.\mu \mathrm{m}^{-3}\right)$ & $136 \pm 38$ & $95 \pm 29$ & $158 \pm 48$ & $133 \pm 35$ & 0.024 \\
\hline Surface underlying podocytes $\left(\mathrm{mm}^{2}\right)$ & $0.252 \pm 0.030$ & $0.314 \pm 0.056$ & $0.254 \pm 0.046$ & $0.294 \pm 0.057$ & 0.046 \\
\hline Area covered by each podocyte $\left(\times 10^{-3} \mathrm{~mm}^{2}\right)$ & $1.68 \pm 0.374$ & $2.40 \pm 0.693 * \dagger$ & $1.60 \pm 0.400$ & $1.71 \pm 0.281$ & 0.008 \\
\hline FPWmes (nm) & $490 \pm 85$ & $499 \pm 41$ & $412 \pm 74$ & $464 \pm 84$ & 0.124 \\
\hline FPWgbm (nm) & $408 \pm 58$ & $472 \pm 74$ & $409 \pm 46$ & $416 \pm 25$ & 0.075 \\
\hline
\end{tabular}

Data are derived from eight randomly selected animals in each group

ANOVA $p$ is the $p$ value by analysis of variance across all four groups

$* p<0.05$ vs respective NPD group, post hoc corrected for multiple testing

$\dagger p<0.001$ vs respective control group, post hoc corrected for multiple testing

$\$ p=0.06$ vs respective control group, post hoc corrected for multiple testing

$G B M$ glomerular basement membrane, $V_{v}$ mes/glom volume fraction of mesangium; FPWmes foot process width on the mesangium;

FPWgbm foot process width on the glomerular basement membrane 


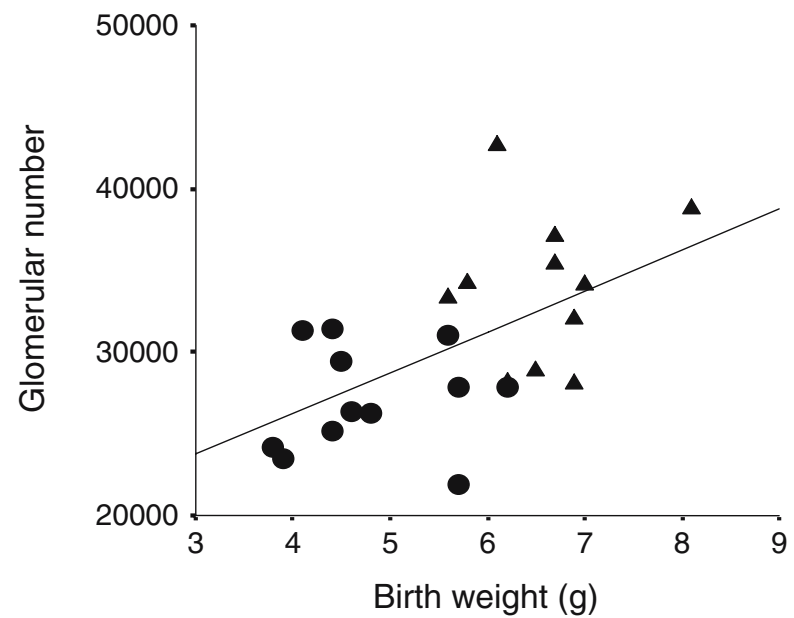

Fig. 2 Relationship of birthweight and glomerular number in female offspring of animals fed normal-protein diet (black triangle) or low-protein diet (black circle) during pregnancy. For all animals, $r=0.57, p=0.005$

\section{Statistical analyses}

Albumin excretion rate was log transformed before analysis to correct for skewed distribution. Values are given as mean \pm SD or median (range). Comparisons between groups were carried out using one-way analysis of variance with the Bonferroni correction for multiple corrections. A twotailed $p$ value $<0.05$ was considered statistically significant. All analyses were performed using SPSS version 11.

\section{Results}

Effects of LPD: comparison of control LPD and control NPD animals

LPD animals were of significantly lower birthweight than NPD animals (Table 1) and the weight of the LPD control animals remained lower than that of the NPD control rats throughout the study (Table 2 and Fig. 1a). Chow consumption, SBP and UAER were similar in the LPD and NPD groups throughout (Fig. 1c). Creatinine clearance at the end of the study was similar in the two groups of animals (Table 2).

Kidney weight and the ratio of kidney weight to body weight were similar in LPD and NPD control animals (Table 3). Glomerular number was significantly reduced in the LPD animals (Table 3), with a significant correlation between birthweight and glomerular number in the combined cohort of LPD and NPD animals (Fig. $2 ; r=0.5 ; p=0.002$ ). There was also a significant negative correlation between mean glomerular number and mean glomerular volume $(r=-0.64$, $p=0.035$, Fig. 3a). Mean glomerular volume, GBM width, volume fraction of mesangium and mesangio-urinary surface and the filtration surface area per glomerulus of peripheral GBM were all similar in LPD and NPD control animals (Table 3). However, the total glomerular filtration surface area per kidney (GBM surface area $\times$ number of glomeruli) was lower in the LPD animals $\left(4,770 \pm 541\right.$ vs $5,779 \pm 1302 \mathrm{~mm}^{2}$; $p=0.05$ ).

Podocyte number, density and the area covered by each podocyte were similar in NPD and LPD control animals, as were foot process width on both mesangium and GBM.

Effects of diabetes: comparison of control and diabetic animals within each diet group

Body weight in LPD and NPD diabetic animals was significantly lower, and chow consumption was significantly higher, than in their respective control groups (Table 2 and Fig. 1a). Blood glucose throughout the study (Fig. 1b) and serum fructosamine at the end of the study (Table 2) were significantly higher in LPD and NPD diabetic animals than in the control animals. UAER increased throughout the study, and creatinine clearance was significantly increased in the two groups of diabetic animals (Table 2 and Fig. 1c). Blood pressure did not change. Kidney weight and kidney weight to body weight ratio were higher in both diabetic groups (Table 3). Mean glomerular volume was increased in the
Fig. 3 Relationship of glomerular number and mean glomerular volume (MGV) in control (a) and diabetic (b) groups of female offspring of animals fed normal-protein diet (control, black triangle; diabetic, open triangle) or low-protein diet (control, black circle; diabetic, open circle) during pregnancy. For control animals, $r=-0.64$, $p=0.035$. For diabetic animals, $r=-0.38, p=0.20$ a

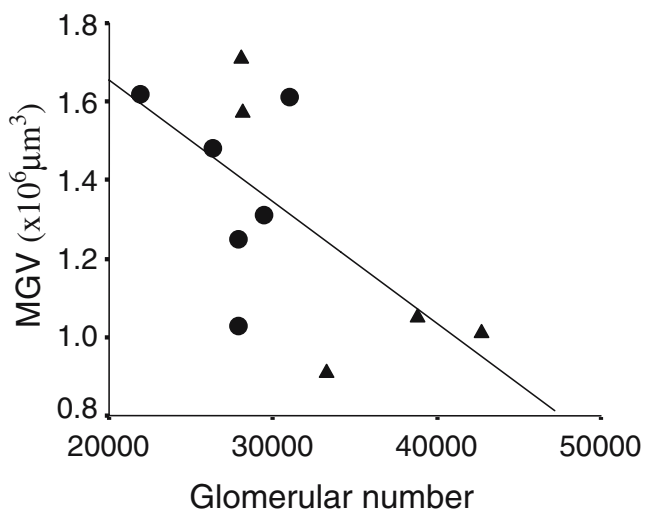

$\mathrm{b}$

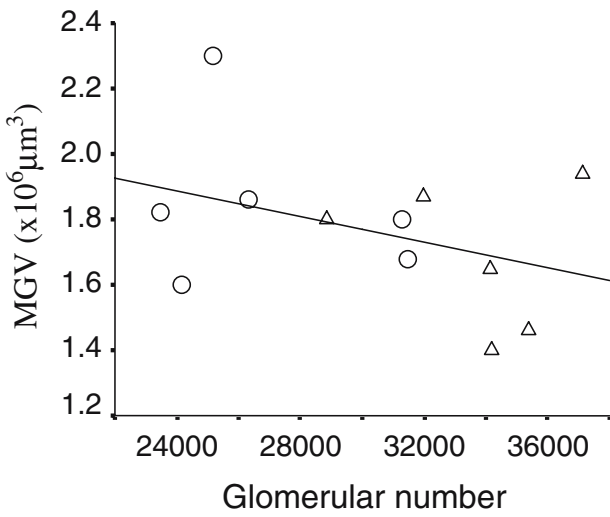


Fig. 4 Relationship of podocyte density and urine albumin excretion rate (log scale) in female offspring of animals fed lowprotein diet (a) (control, black circle; diabetic, open circle) or normal-protein diet (b) (control, black triangle; diabetic, open triangle) during pregnancy. For the LPD animals, $r=-0.68$, $p=0.004$. For the NPD animals, $r=-0.15, p=0.592$

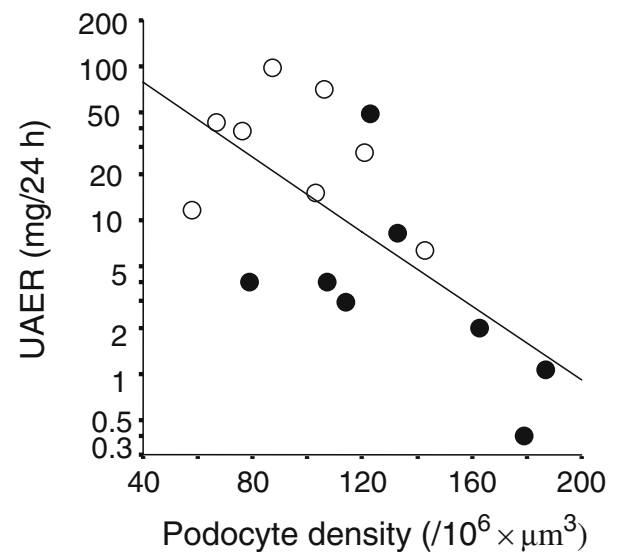

b

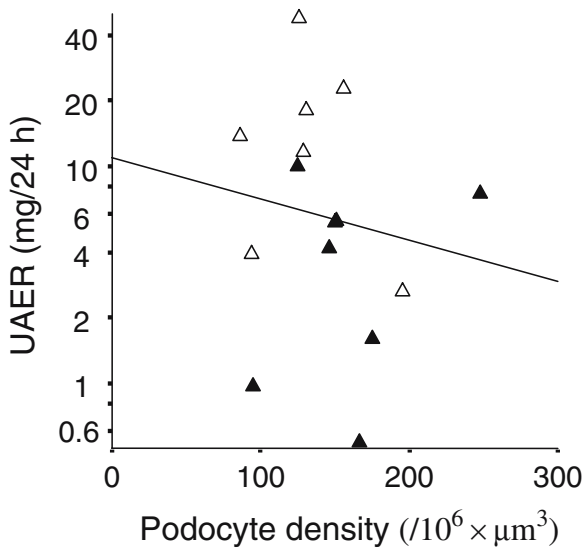

diabetic groups compared to their respective controls $(p<0.05)$ as was GBM width, although this difference did not reach statistical significance ( $p=0.06$ for both; Table 3 ). In contrast to the non-diabetic animals, the correlation between glomerular number and mean glomerular volume in the diabetic animals did not reach significance (Fig. $3 b ; r=-0.38$, $p=0.20)$. GBM width correlated with UAER at week 28 of diabetes in both LPD $(r=0.53, p=0.008)$ and NPD animals $(r=0.42, p=0.046)$. The greater mesangio-urinary surface area in the diabetic animals was significant in the LPD group only, suggesting that changes were occurring in the mesangium.

The absolute number of podocytes was not altered by diabetes (Table 3). However, because of the increase in glomerular volume, podocyte density was lower (ANOVA $p=0.024$ ) and the total surface covered by the podocytes was greater (ANOVA $p=0.046$ ) in the diabetic animals, although the differences between individual groups did not reach conventional statistical significance. The area covered by each podocyte was increased in the LPD diabetic animals compared to their respective control group. Foot process width on mesangium and GBM was similar in diabetic and control animals.

Interaction of diabetes and LPD: comparison of LPD and NPD diabetic animals

Body weight was significantly lower in the LPD diabetic animals compared to the NPD diabetic animals (Table 2 and Fig. 1a). There were no differences in chow consumption, serum fructosamine, blood pressure, UAER and creatinine clearance between LPD and NPD diabetic animals. Kidney weight was significantly lower in the LPD diabetic animals, but the kidney weight to body weight ratio was similar. By design, glomerular number was significantly lower in the LPD diabetic animals. Mean glomerular volume was similar $\left(1.84 \pm 0.24\right.$ vs $\left.1.69 \pm 0.22 \times 10^{6} \mu^{3}, p=0.271\right)$ and no differences were found in GBM width, volume fraction of mesangium, mesangio-urinary surface or podocyte number $(138 \pm 37$ vs $174 \pm 35, p=0.095)$. Podocyte density was reduced (ANOVA $p=0.024$ ), although the difference in podocyte density between the LPD and NPD diabetic animals did not reach significance $(95 \pm 29$ vs $133 \pm 35$ per $\left.10^{6} \mu^{3}, p=0.305\right)$. However, the area covered by each podocyte was significantly greater in the LPD diabetic animals compared to the NPD diabetic animals $(2.40 \pm 0.693$ vs $\left.1.71 \pm 0.281 \times 10^{-3} \mathrm{~mm}^{2}, p<0.05\right)$. In the LPD diabetic animals, podocyte density $(r=-0.68, p=0.004$; Fig. 4$)$ and area covered by each podocyte $(r=0.481, p=0.017)$ correlated with UAER at 28 weeks of diabetes. No such relationships were seen in the NPD diabetic animals (density $r=-0.15, p=0.59$, Fig. 4; area $r=0.269, p=0.214)$. Foot process widths on mesangium and GBM were similar in diabetic LPD and NPD animals.

In the whole cohort of animals, mean glomerular volume correlated with UAER at 28 weeks of diabetes $(r=0.67$, $p<0.001)$ and creatinine clearance $(r=0.48, p<0.05)$.

\section{Discussion}

As expected from previous studies [23], animals whose dams were fed LPD were of lower birthweight and had fewer glomeruli than animals whose dams were fed NPD. Protein restriction in pregnancy is associated with increased apoptosis of mesenchymal cells at the start of rat metanephrogenesis, so that fewer precursors are available to differentiate into nephrons [24]. Angiotensin may also play a role, as renal expression of the angiotensin II type 2 receptor is reduced in animals exposed to LPD in utero, with a greater and more prolonged pressor response to infusion of angiotensin II [25].

Glomerular number was reduced by approximately $20 \%$. The interrelationship of low birthweight, glomerular number and glomerular volume is supported by the positive correlations between birthweight and glomerular number and the inverse correlation between glomerular number and mean glomerular volume. However, the total filtration surface area was lower in the LPD than in the NPD control animals. Despite this, no deleterious effects were observed on UAER or creatinine clearance. Glomerular filtration rate is reported to be normal at 19 weeks in a similar rat model 
of LPD as used in this study [23], although in another study UAER was increased by 20 weeks of age [26]. In small, long-term studies of individuals of low birthweight, glomerular filtration rate and UAER are normal in early adulthood [27, 28].

Many previous studies have described changes in glomerular volume $[23,29,30]$ secondary to a reduction in glomerular number produced by a variety of causes. However, a detailed systematic analysis of kidney morphology in low birthweight animals has not been described previously. No abnormalities were found in any of the histological parameters examined in the LBW compared to NBW animals. Thus for the 40 weeks duration of this study, a reduced number of glomeruli does not appear to be deleterious to the kidney. However, we cannot exclude the possibility that pathological changes might occur over a longer time or if the reduction in glomerular number were more marked, as in uninephrectomy. In a rat model of oligonephronia induced in utero by gentamicin and using descriptive histological techniques only, mesangial lesions and glomerular sclerosis were more common than in control animals at 24 months [31]. A parallel may be drawn with renal transplant donors, where longitudinal studies have shown no adverse effects in the early years after nephrectomy [32] but an increased prevalence of microalbuminuria and hypertension after 12-31 years [33].

Epidemiological studies have suggested that individuals with a birthweight $<2.5 \mathrm{~kg}$ are at increased risk of developing end-stage renal disease [7, 34] or albuminuria [6] compared to those with a birthweight $>2.5 \mathrm{~kg}$. Low birthweight, with fewer glomeruli, may provide a partial explanation for the excess end-stage renal disease in African Americans compared to Caucasians [7]. However, a second insult may be necessary before the detrimental effects of the reduced nephron mass become apparent. Congenital nephron deficits may interact with environmental and genetic factors to generate glomerulosclerosis [35]. In children with nephrotic syndrome [36] or IgA nephropathy [37], those with intrauterine growth retardation had higher blood pressure and more rapidly progressive disease than those of normal birth weight.

Our LPD animals with streptozotocin-induced diabetes were subjected to such a second insult. The LPD and NPD diabetic animals showed the classical functional and structural changes associated with early human and experimental diabetic glomerulosclerosis. UAER, creatinine clearance, mean glomerular volume and basement membrane thickness were all increased. Changes in these parameters were generally similar in the LPD and NPD diabetic animals, the only difference being that the average area covered by each podocyte was greater in the LPD diabetic animals compared to the NPD diabetic group. Significant correlations between both podocyte density and the area covered by each podocyte with UAER were observed only in the LPD animals. The significance of these changes is unclear but the podocyte may be particularly sensitive to changes in intraglomerular pressure with increased mechanical stretch. This is likely to be higher in the LPD compared to NPD animals
[38]. Thus these podocyte changes may be an important early indicator of significant structural and functional damage. The podocyte changes per se may enhance proteinuria and contribute to later damage. Foot process broadening and effacement and a reduction in podocyte number are recognised in diabetes [39-42].

Thus overall, there was no compelling evidence that animals of low birthweight, and thus with fewer glomeruli, developed the histological changes of diabetic glomerulosclerosis more rapidly than animals of NBW with significantly higher numbers of glomeruli. It should be noted that although the streptozotocin-induced diabetes model exhibits functional and structural changes which parallel those seen in early human diabetic nephropathy, progressive renal impairment and the more advanced structural changes of human diabetic glomerulosclerosis do not develop. Indeed, there is currently no satisfactory animal model that demonstrates the classical characteristics of progressive diabetic glomerulosclerosis. However, it is conceivable that reduced glomerular number may influence the loss of glomerular filtration rate later in the disease process. Second, our animals were not hypertensive. The presence of systemic hypertension exacerbates most forms of kidney disease and does interact with hyperglycaemia to induce greater structural damage [43, 44]. Although frank systemic hypertension is not a feature of early human diabetic nephropathy, it is possible that with the addition of a third insult, hypertension, LPD diabetic animals may have more rapidly progressive renal disease than NPD animals.

The evidence that LBW humans are more likely to develop kidney disease is conflicting. Although initial studies suggested this was the case [11, 12], two recent studies in type 1 diabetes found no influence of low birthweight on the subsequent development of diabetic nephropathy $[45,46]$. In a small series, no relationship between birthweight and glomerular number and volume was found in patients with type 2 diabetes [47]. However, in the Pima Indians, the prevalence of increased UAER is higher in LBW compared to NBW individuals [48].

In conclusion, LBW animals have a reduced number of glomeruli and a reduced total glomerular filtration surface area. However, over the duration of this study, renal structural or functional abnormalities did not develop. When a second renal insult, diabetes without hypertension, is added, no change in structure or function was observed, over and above the expected changes of diabetes. Thus for the duration of this study, a $20 \%$ reduction in glomerular number had no deleterious effects on renal structure and function in animals with or without diabetes. Further work, of longer duration and perhaps in animal models of diabetes with hypertension in which progressive renal impairment occurs, is necessary to clarify the impact of LBW on the development of kidney disease.

Acknowledgements The study was funded by project grants from Diabetes UK, the Danish Diabetes Association and the Danish Medical Research Council. We are grateful to Denise Reid and Rob Stewart for their excellent animal care, and to Heather Gilbert, Karen Mathiassen, Kirsten Nyborg, Vivian Thompson and Tracey Davey for technical help. 


\section{References}

1. Barker DJ, Bull AR, Osmond C, Simmonds SJ (1990) Fetal and placental size and the risk of hypertension in adult life. Br Med J 302:259-262

2. Holland FJ, Stark O, Ades AE, Peckham LS (1993) Birth weight and body mass index in childhood, adolescence and adulthood as predictors of blood pressure at age 36 . J Epidemiol Community Health 47:432-435

3. Goldstein RS, Hook J, Bond JT (1979) The effects of maternal protein deprivation on renal development and function in neonatal rats. J Nutr 109:949-957

4. Merlet-Benichou C, Gilbert T, Muffat-Joly M, Lelievre-Pegorier M, Lerpy B (1994) Intrauterine growth retardation leads to a permanent nephron deficit in the rat. Pediatr Nephrol 8:175-180

5. Brenner BM, Garcia DL, Anderson S (1988) Glomeruli and blood pressure: less of one and more of the other? Am J Hypertension 1:333-347

6. Hoy WE, Rees M, Kile E, Mathews JD, Wang Z (1999) A new dimension to the Barker hypothesis: low birthweight and susceptibility to renal disease. Kidney Int 56:1072-1077

7. Lackland DT, Egan BM, Fan ZJ, Syddall HE (2001) Low birth weight contributes to the excess prevalence of end-stage renal disease in African Americans. J Clin Hypertens 3:29-31

8. Na YW, Yang HJ, Choi JH et al (2002) Effect of intrauterine growth retardation on the progression of nephrotic syndrome. Am J Nephrol 22:463-467

9. Marshall SM (2004) Recent advances in diabetic nephropathy. Clin Med 4:277-282

10. Østerby R, Parving HH, Nyberg G, Hommel E, Mauer SM, Steffes MW (1988) A strong correlation between glomerular filtration rate and filtration surface area in diabetic nephropathy. Diabetologia 31:256-270

11. Rossing P, Tarnow L, Nielsen FS, Boelskifte S, Brenner BM, Parving HH (1995) Short stature and diabetic nephropathy. Br Med J 310:296-297

12. Microalbuminruia Collaborative Study Group (1999) Predictors of the development of microalbuminuria in patients with type 1 diabetes mellitus: a seven-year prospective study. Diabetic Med 16:918-925

13. Jones SE, Bilous RW, Flyvbjerg A, Marshall SM (2001) Intrauterine environment influences glomerular number and the acute renal adaptation to experimental diabetes. Diabetologia 44:721-728

14. Baddeley A, Gundersen H, Cruz-Orive L (1986) Estimation of surface area from vertical sections. J Microsc 142:259-276

15. Nyengaard J, Bendtsen T (1990) A practical method to count the number of glomeruli in the kidney as exemplified in various animal species. Acta Stereologica 9:243-258

16. White KE, Bilous RW (2000) Type 2 diabetic patients with nephropathy show structural-functional relationships that are similar to type 1 disease. J Am Soc Nephrol 11:1667-1673

17. White KE, Bilous RW (2004) Estimation of podocyte number: a comparison of methods. Kidney Int 66:663-667

18. Weibel E, Gomez D (1962) A principle for counting tissue structures on random sections. J Appl Physiol 17:343-348

19. Østerby R, Gundersen HJ, Nyberg G, Aurell M (1987) Advanced diabetic glomerulopathy. Quantitative structural characterization of nonoccluded glomeruli. Diabetes 36:612-619

20. Bjórn SF, Bangstad HJ, Hanssen KF et al (1995) Glomerular epithelial foot processes and filtration slits in IDDM patients. Diabetologia 38:1197-1204

21. Flyvbjerg A, Marshall S, Frystyk J, Hansen K, Harris A, Orskov H (1992) Octreotide administration in diabetic rats: effects on renal hypertrophy and urine albumin excretion. Kidney Int 41:805-812

22. Boye N, Ingerslev J (1988) Rapid and inexpensive microdetermination of serum fructosamine results in diabetics, uraemics, diabetics with uraemia and healthy subjects. Scand J Lab Invest 48:779-783
23. Langley-Evans SC, Welham SJM, Jackson AA (1999) Fetal exposure to a maternal low protein diet impairs nephrogenesis and promotes hypertension in the rat. Life Sci 64:965-974

24. Welham SJM, Wade A, Woolf AS (2002) Protein restriction in pregnancy is associated with increased apoptosis of mesenchymal cells at the start of rat metanephrogenesis. Kidney Int 61:1231-1242

25. McMullen S, Gardner DS, Langley-Evans SC (2004) Prenatal programming of angiotensin II type 2 receptor expression in the rat. Br J Nutr 91:133-140

26. Nwagwu MO, Cook A, Langley-Evans SC (2000) Evidence of progressive deterioration of renal function in rats exposed to a maternal low protein diet in utero. Br J Nutr 83:79-85

27. Vasarhelyi B, Dobos M, Reusz GS, Szabo A, Tulassay T (2000) Normal kidney function and elevated natriuresis in young men born with low birth weight. Pediatr Nephrol 15:96-100

28. Kistner A, Celsi G, Vanpee M, Jacobson SH (2000) Increased blood pressure but normal renal function in adult women born preterm. Pediatr Nephrol 15:215-220

29. Merlet-Benichou C, Gilbert T, Moffat-Joly M, Lievre-Pegorier M, Leroy B (1994) Intrauterine growth retardation leads to a permanent nephron deficit in the rat. Pediatr Nephrol 8:175-180

30. Lucas SR, Costa Silva VL, Miraglia SM, Zaladek Gil F (1997) Functional and morphometric evaluation of offspring kidney intrauterine undernutrition. Pediatr Nephrol 11:719-723

31. Gilbert T, Lelievre-Pegorier M, Merlet-Benichou C (1991) Long-term effects of mild oligonephronia induced in utero by gentamycin in the rat. Pediatr Res 30:450-456

32. Tapson JS, Hodson A, Marshall SM, Wilkinson R (1988) Urinary enzyme excretion after donor nephrectomy. Nephron 48:121-131

33. Saran R, Marshall SM, Madsen R, Keavey P, Tapson JS (1997) Long-term follow-up of kidney donors: a longitudinal study. Nephrol Dial Transplant 12:1615-1621

34. Fan Z, Lipsitz S, Egan B, Lackland D (2000) The impact of birth weight on the racial disparity of end-stage renal disease. Ann Epidemiol 10:459

35. Zeng F, Striker GE, Exposito C, Lupia E, Striker LJ (1998) Strain differences rather than hyperglycaemia determine the severity of glomerulosclerosis in mice. Kidney Int 54:1999-2007

36. Sheu JN, Chen JH (2001) Minimal change nephrotic syndrome in children with intrauterine growth retardation. Am J Kidney Dis 37:909-914

37. Zidar N, Cavie MA, Kenda RB, Koselj M, Ferluga D (1998) Effect of intrauterine growth retardation on the clinical course and prognosis of $\operatorname{IgA}$ glomerulonephritis in children. Nephron 79:28-32

38. Petermann AT, Hiromura K, Blonski M et al (2002) Mechanical stress reduces podocyte proliferation in vitro. Kidney Int 61:40-50

39. White KE, Bilous RW, Marshall SM et al (2002) Podocyte number in normotensive type 1 diabetic patients with albuminuria. Diabetes 51:3083-3089

40. White KE, Bilous RW on behalf of the Diabiopsies Study Group (2004) Structural alterations to the podocyte are related to proteinuria in type 2 diabetic patients. Nephrol Dial Transplant 19:1437-1440

41. Steffes MW, Schmidt D, McCrery R, Basgen JM; International Diabetic Nephropathy Study Group (2001) Glomerular cell number in normal subjects and in type 1 diabetic patients. Kidney Int 59:2104-2113

42. Pagtalunan ME, Miller PL, Jumping-Eagle S et al (1997) Podocyte loss in progressive glomerular injury in type II diabetes. J Clin Invest 99:342-348

43. Janssen U, Riley SG, Vassiliadou A, Floege J, Philips AO (2003) Hypertension superimposed on type II diabetes in Goto Kazizaki rats induces progressive nephropathy. Kidney Int 63:2162-2170

44. Cooper ME, Allen TJ, MacMillan PA, Clarke BE, Jerums G, Doyle AE (1989) Enalapril retards glomerular basement membrane thickening and albuminuria in the diabetic rat. Diabetologia 32:326-328 
45. Eshoj O, Vaag A, Borch-Johnsen K, Feldt-Rasmussen B, BeckNielsen H (2002) Is low birth weight a risk factor for the development of diabetic nephropathy in patients with type 1 diabetes? A population-based case-control study. J Intern Med 252:524-528

46. Jacobsen P, Rossing P, Tarnow L, Hovind P, Parving HH (2003) Birth weight - a risk factor for progression in diabetic nephropathy? J Intern Med 253:343-350
47. Nyengaard JR, Bendtsen TF, Mogensen CE (1996) Low birth weight - is it associated with few and smaller glomeruli in normal subjects and NIDDM patients? Diabetologia 39:1634-1637

48. Nelson RG, Morgenstern H, Bennett PH (1998) Birth weight and renal disease in Pima Indians with type 2 diabetes mellitus. Am J Epidemiol 148:650-656 